\title{
Incidence and severity of nausea and vomiting in a group of maintenance hemodialysis patients
}

\author{
Mohammad Reza Asgari ${ }^{1}$, Fatemeh Asghari ${ }^{1,2}$, Ali Asghar Ghods ${ }^{1^{*}}$, Raheb Ghorbani ${ }^{3}$, Nahid Hoshmand \\ Motlagh $^{4}$, Fatemeh Rahaei ${ }^{3,2}$ \\ ${ }^{1}$ Nursing Care Research Center, Department of Medical-Surgical Nursing, Faculty of Nursing and Allied Health, Semnan University of Medical \\ Sciences, Semnan, Iran \\ ${ }^{2}$ Student Research Committee, Faculty of Nursing, Semnan University of Medical Sciences, Semnan, Iran \\ ${ }^{3}$ Social Determinants of Health Research Center, Department of Social Medicine, Faculty of Medicine, Semnan University of Medical Sciences, \\ Semnan, Iran \\ ${ }^{4}$ Department of Allied Health, Faculty of Nursing and Allied Health, Semnan University of Medical Sciences, Semnan, Iran
}

\section{ART I C L E IN F O}

Article Type:

Original

Article History:

Received: 19 June 2016

Accepted: 31 August 2016

Published online: 3 September 2016

Keywords:

Chronic kidney disease

Hemodialysis

Nausea

Vomiting

\begin{abstract}
A B S T R A C T
Introduction: Chronic kidney disease (CKD) is a rising problem across the world, including Iran. Most of the patients will require hemodialysis for survival. Despite the great progress has been made in the hemodialysis equipment, but it is still associated with complications. Nausea and vomiting are common complication of during hemodialysis, which leads to unpleasant feeling in patients.

Objectives: This study aimed to determine incidence and severity of nausea and vomiting in a group of maintenance hemodialysis patients.

Patients and Methods: This is a descriptive and analytical study on 60 hemodialysis patients of dialysis wards in Semnan University of Medical Sciences. Verbal Numeric Rating Scale (VNRS) and Korttila vomiting severity scale were used to measure the severity of nausea and vomiting during hemodialysis respectively.

Results: In this study, the incidence of nausea and vomiting during hemodialysis were $28.3 \%$ and $11.7 \%$, respectively. Meanwhile, the mean severity of nausea was 1.15 and the mean rank of vomiting was 2.08 .

Conclusion: The results of the study showed a relatively high incidence of nausea and vomiting in patients undergoing hemodialysis, hence nurses must consider these problems by suitable measures to prevent the occurrence of the these unpleasant feelings in the patients during hemodialysis.
\end{abstract}

Implication for health policy/practice/research/medical education:

Despite the great progress has been made in the hemodialysis equipment, but it is still associated with complications. Nausea and vomiting are common complication of during hemodialysis, which leads to unpleasant feeling in patients. Given the importance of nausea and vomiting developed during hemodialysis and the need to know their incidence in order to evaluate the quality of hemodialysis and plan healthcare policies in this area, the present study was conducted to determine the incidence and severity of nausea and vomiting during hemodialysis in a group patients to provide a more accurate image of hemodialysis quality. The results of the study showed a relatively high incidence of nausea and vomiting in our patients undergoing hemodialysis.

Please cite this paper as: Asgari MR, Asghari F, Ghods AA, Ghorbani R, Hoshmand Motlagh N, Rahaei F. Incidence and severity of nausea and vomiting in a group of maintenance hemodialysis patients. J Renal Inj Prev. 2017;6(1):49-55. DOI: 10.15171/jrip.2017.09.

\section{Introduction}

In the past decade, the landscape of health has changed in terms of disease and death due to the advances in science and technology and the changes in lifestyle (1). Communicable and infectious diseases have gotten under control and chronic and metabolic diseases have replaced them (2). Chronic renal failure (CRF) is one of the major causes of death and disability caused by chronic disease across the world (3).

$\mathrm{CRF}$ is also referred to as chronic kidney disease (CKD). CKD refers to an advanced and irreversible kidney failure that is often progressive. In general, CKD refers 
to a condition in which kidney damage or decreased glomerular filtration rate (GFR) persist for three months or longer. This disease eventually leads to end-stage renal disease (ESRD). ESRD is actually the final stage of CKD in which kidney function is no longer adequate to sustain life (4).

The incidence of CKD is increasing across the world for various reasons. On average, $10 \%$ of the population suffers from some degree of CKD. In 2000, the global number of CKD patients under treatment across the world was approximately 1.1 million, reaching 2654000 by the end of 2009 , revealing an increase of $6 \%-7 \%$, which is more significant than the global population growth rate. The proportion of hemodialysis patients is estimated to reach 3500000 by 2020 (4).

The growth rate of this disease is about $12 \%$ per year in Iran, which is higher than the global average (5). As reported by the Nephrology and Kidney Transplantation Research Center of Iran, about 29000 patients with CKD were under treatment at the end of 2007, 14000 (48.5\%) of whom were under hemodialysis (6). At the end of 2011, the number of patients with CKD was about 40000 in Iran (7).

Given that in the final stage of CKD, the kidney function is no longer adequate to sustain life, the patient develops a permanent need for renal replacement therapies at this stage, including dialysis or kidney transplantation (8). In patients with CKD, dialysis is performed through two methods, including hemodialysis and peritoneal dialysis (4). Hemodialysis is the most common treatment used in ESRD. Hemodialysis patients require this particular treatment for the rest of their life or until they receive a successful kidney transplant. Hemodialysis is usually performed 3 times per week and for 3-4 hours every session (9).

Since the second half of the 20th century, hemodialysis has saved the lives of numerous CKD patients and improved their quality of life (10). Although it can lead to increased patient survival, hemodialysis is incapable of altering the natural course of the underlying kidney disease or completely replaces the kidney function. Despite the great advances in hemodialysis technologies, this method is still not without the complications during hemodialysis (11), as CKD and its conservative treatment (i.e. hemodialysis) can lead to many physical, psychological and social problems for the patients (7).

Various complications, including hypotension, muscle cramps, disequilibrium syndrome, nausea and vomiting and dyspnea, with varying degrees of incidence may occur to the patient during hemodialysis, and nurses need to be familiar with the details of these complications. Preventing complications before they develop is of utmost importance. The early detection and modification of lifethreatening complications can save the life of patients. Some hemodialysis complications do not threaten the life of the patients but deteriorate their quality of life. Resolving these problems leads to a greater longevity and a better quality of life (4).
Nausea and vomiting are one of the most common complications during hemodialysis. In the study of Chong and Tan on the incidence of gastrointestinal symptoms in Asian patients under regular hemodialysis, anorexia, nausea, vomiting and an early feeling of fullness when eating were experienced to a significant degree. In the study, incidence of nausea and vomiting was reported as $18.2 \%$ and $9.8 \%$, respectively (12). Nevertheless, in a study conducted in Iran, the incidence of nausea and vomiting were more common during hemodialysis and up to $25.8 \%$ of the cases reported these symptoms (13).

Nausea and vomiting occur for various reasons upon the initiation of hemodialysis. Many patients experience these symptoms during hemodialysis due to the rapid drop in blood pressure or urea (14). Other causes of nausea and vomiting include fever response to municipal water and other materials, disequilibrium syndrome, anxiety, and general causes of nausea and vomiting (4). The multiple etiology of the effects of ESRD and its treatment on the digestive system, the patient's diet, medication regimen, and developed disabilities are also considered major causes of nausea and vomiting. Fluid overload is also associated with mucosal edema in the gastrointestinal system (along with early satiety), nausea, vomiting, and diarrhea (12). Nausea and vomiting should be further examined and prevented, as they cause complications during hemodialysis patients. Electrolyte and water imbalance (dehydration) can be considered a major complication of vomiting. The electrolyte and water imbalance following vomiting disrupts the goals of hemodialysis -that is, to maintain a proper and safe concentration of serum electrolytes (4). Nausea and vomiting make dialysis unpleasant for patients and may thus lead to the early discontinuation of dialysis and thereby an undesirable adequacy of dialysis despite the high costs of treatment (15).

\section{Objectives}

Given the importance of nausea and vomiting developed during hemodialysis and the need to know their incidence in order to evaluate the quality of hemodialysis and plan healthcare policies in this area, the present study was conducted to determine the incidence and severity of nausea and vomiting during hemodialysis in our patients so as to provide a more accurate image of hemodialysis quality and to facilitate the devise of plans and strategies for the control and prevention of these complications based on their incidence.

\section{Patients and Methods}

Subjects

The present descriptive analytical study was conducted on patients selected through convenience sampling. For this purpose, all the eligible patients from the hemodialysis units of hospitals affiliated to Semnan University of Medical Sciences $(n=60)$ were examined in terms of the incidence and severity of nausea and vomiting during hemodialysis. The study inclusion criteria consisted of being sober, not taking any nausea and vomiting medicines from six hours 
before hemodialysis, having been under hemodialysis for at least three months, age over 20, and requiring 3-4-hour hemodialysis sessions a week.

The questionnaire used consisted of two parts. The first part inquired about the patients' demographic data, including age, gender, occupation, place of residence, level of education, and duration of dialysis. The second part consisted of a tool for measuring the severity of nausea and vomiting. Nausea was measured by the Verbal Numeric Rating Scale (VNRS). This tool rates the subjects on a scale from 0 to 10 , with 0 indicating no nausea and 10 suggesting very severe nausea. The severity of nausea was described with this scale according to the following instructions: A score of zero was taken as the lack of nausea, a score of 1-3 as mild nausea, 4-6 as moderate nausea, $7-9$ as severe nausea and 10 as very severe nausea. The severity of vomiting was determined using the Korttila scale. In this scale, non-retching is taken as the lack of vomiting, retching less than three times with or without gastric emptying as mild vomiting, 3-5 times of retching with or without gastric emptying as moderate vomiting, and more than 5 times of retching with or without gastric emptying as severe vomiting (16). The reliability of the tools was determined through a pilot study of the first 20 subjects using the test-retest method, which was calculated as $97 \%$ for the VNRS and $94 \%$ for the Korttila scale.

The incidence and severity of nausea and vomiting during hemodialysis were determined in one stage in the patients. At the end of each hemodialysis session and after removing the hemodialysis needle and dressing the sites of vascular access, the researcher visited the patient with a ward nurse (as the project colleague) and explained the objectives and methods of the study to the patient. He then used the VNRS and Korttila scale to measure the patient's severity of nausea and vomiting during hemodialysis by asking questions and then filled out the questionnaire. To maintain consistent conditions for data collection, it was arranged with the ward head nurse to have the selected patients undergo dialysis at the same place, same shift, and with the same dialysis machine at a temperature of $37^{\circ} \mathrm{C}$ and with bicarbonate solution. Environmental conditions such as light, sound, smell and temperature were kept consistent during the three sessions. The bed was positioned at a 30-degree angle for all the patients during the study.

\section{Ethical issues}

The research followed the tenets of the Declaration of Helsinki; informed consent was obtained; and the research was approved by the ethical committee of Semnan University of Medical Sciences (Ethical code: 92/372055). Ethical considerations were respected during the study. The researcher first introduced himself to the subjects and briefed them on the study objectives and methods and ensured them about the confidentiality of their data and answered their questions; the subjects then submitted their written consent to participate in the study (Research design code 579).

\section{Statistical analysis}

To analyze the data, Mann-Whitney U test and Spearman's correlation coefficient were used at a significance level of $5 \%$ in addition to calculating the indices of central tendency and dispersion and drawing the frequency distribution tables. The software used was SPSS 18 .

\section{Results}

Of all the patients examined, $56.7 \%(n=34)$ were male; the mean \pm standard deviation (SD) of the patients' age was $59.5 \pm 14.8$ years, ranging from a minimum of 23 years and a maximum of 85 . A total of $90 \%$ of the patients were educated up to high school; $91.7 \%(\mathrm{n}=55)$ lived in urban areas and $38.3 \%(n=23)$ were retired. The mean \pm SD of their disease duration was $46.3 \pm 42.6$ months, ranging from a minimum of four months and a maximum of 209, and with a median of 30.5 .

\section{Incidence and severity of nausea}

In line with the study objectives and as shown in Table 1 regarding the incidence and severity of nausea, the incidence of nausea during dialysis was $28.3 \%$, which was mild in $11.7 \%$ of the cases, moderate in $13.3 \%$, and severe in $3.3 \%$; none of the patients experienced very severe nausea. The mean severity of nausea was $1.15 \pm 2.08$ in the patients.

\section{Incidence and severity of vomiting}

As shown in Table 2 regarding the incidence and severity of vomiting, the incidence of vomiting was $11.7 \%$ in the patients, which was mild in $8.4 \%$ of the cases and moderate in $3.3 \%$; none of the patients experienced very severe vomiting. The mean rank of vomiting severity was 2.08 in the patients.

As shown in Table 3 regarding the relationship between the severity of nausea and the demographic variables, a significant relationship was observed between gender and the severity of nausea, as the severity of nausea was higher in women than in men $(P=0.034)$; however, no significant

Table 1. Absolute and relative frequency of subjects in terms of incidence and severity of nausea during hemodialysis

\begin{tabular}{lcc}
\hline Severity of nausea & Number & Percent \\
\hline Lack of nausea & 43 & 71.7 \\
Mild & 7 & 11.7 \\
Moderate & 8 & 13.3 \\
Severe & 2 & 3.3 \\
Very severe & 0 & 0 \\
Mean severity of nausea & \multicolumn{2}{c}{$1.15 \pm 2.08$} \\
\hline
\end{tabular}

Table 2. Absolute and relative frequency of subjects in terms of incidence and severity of vomiting during hemodialysis

\begin{tabular}{lcc}
\hline Severity of vomiting & Number & Percent \\
\hline Lack of vomiting & 53 & 88.3 \\
Mild & 5 & 8.4 \\
Moderate & 2 & 3.3 \\
Severe & 0 & \\
Mean rank of severity of vomiting & & 2.08 \\
\hline
\end{tabular}


Table 3. Distribution, mean, SD, median, IQR of severity of nausea in hemodialysis patients according to gender, age, educational level, residential area, job, and disease duration

\begin{tabular}{|c|c|c|c|c|c|c|c|c|c|c|c|c|c|c|c|}
\hline \multirow{3}{*}{ Characteristics } & \multirow{3}{*}{$\mathbf{n}$} & \multicolumn{8}{|c|}{ Severity of nausea } & \multirow{3}{*}{ Mean } & \multirow{3}{*}{ SD } & \multirow{3}{*}{ Median } & \multirow{3}{*}{ IQR } & \multirow{3}{*}{$r$} & \multirow{3}{*}{$P$} \\
\hline & & \multicolumn{2}{|c|}{ No Nausea } & \multicolumn{2}{|c|}{ Mild } & \multicolumn{2}{|c|}{ Moderate } & \multicolumn{2}{|c|}{ Severe } & & & & & & \\
\hline & & No. & $\%$ & No. & $\%$ & No. & $\%$ & No. & $\%$ & & & & & & \\
\hline Gender & & & & & & & & & & & & & & - & 0.034 \\
\hline Female & 26 & 15 & 57.7 & 4 & 15.4 & 6 & 23.1 & 1 & 3.8 & 1.77 & 2.45 & 0.00 & 4.25 & & \\
\hline Male & 34 & 28 & 82.4 & 3 & 8.8 & 2 & 5.9 & 1 & 2.9 & 0.68 & 1.63 & 0.00 & 0.00 & & \\
\hline Age (y) & & & & & & & & & & & & & & -0.220 & 0.091 \\
\hline$<50$ & 15 & 11 & 73.3 & 2 & 13.3 & 2 & 13.3 & - & - & 0.93 & 1.71 & 0.00 & 2.00 & & \\
\hline $50-59$ & 14 & 7 & 50.0 & 3 & 21.4 & 3 & 21.4 & 1 & 7.1 & 2.21 & 2.75 & 1.00 & 5.00 & & \\
\hline $60-69$ & 12 & 8 & 66.7 & 1 & 8.3 & 3 & 25.0 & - & - & 1.25 & 1.96 & 0.00 & 3.50 & & \\
\hline$\geq 70$ & 19 & 17 & 89.5 & 1 & 5.3 & - & - & 1 & 5.3 & 0.47 & 1.64 & 0.00 & 0.00 & & \\
\hline Educational level & & & & & & & & & & & & & & 0.055 & 0.677 \\
\hline Illiterate & 9 & 7 & 77.8 & 2 & 22.2 & - & - & - & - & 0.56 & 1.13 & 0.00 & 1.00 & & \\
\hline Primary & 22 & 15 & 68.2 & 3 & 13.6 & 3 & 13.6 & 1 & 4.5 & 1.27 & 2.19 & 0.00 & 2.00 & & \\
\hline Intermediate & 11 & 10 & 90.9 & 1 & 9.1 & - & - & - & - & 0.27 & 0.90 & 0.00 & 0.00 & & \\
\hline Secondary & 12 & 5 & 41.7 & 1 & 8.3 & 5 & 41.7 & 1 & 8.3 & 2.75 & 2.80 & 3.00 & 4.75 & & \\
\hline Diploma+ & 6 & 6 & 100 & - & - & - & - & - & - & 0.00 & 0.00 & 0.00 & 0.00 & & \\
\hline Residential area & & & & & & & & & & & & & & - & 0.756 \\
\hline City & 55 & 39 & 70.9 & 7 & 12.7 & 7 & 12.7 & 2 & 3.6 & 1.18 & 2.12 & 0.00 & 2.00 & & \\
\hline Rural & 5 & 4 & 80.0 & - & - & 1 & 20.0 & - & - & 0.80 & 1.79 & 0.00 & 2.00 & & \\
\hline Job & & & & & & & & & & & & & & - & 0.257 \\
\hline Housekeeper & 22 & 13 & 59.1 & 4 & 18.2 & 4 & 18.2 & 1 & 4.5 & 1.68 & 2.48 & 0.00 & 2.75 & & \\
\hline Retired & 23 & 19 & 82.6 & - & - & 3 & 13.0 & 1 & 4.3 & 0.87 & 2.01 & 0.00 & 0.00 & & \\
\hline Others & 15 & 11 & 73.3 & 3 & 20.0 & 1 & 6.7 & - & - & 0.80 & 1.42 & 0.00 & 2.00 & & \\
\hline Disease duration (mon) & & & & & & & & & & & & & & -0.095 & 0.469 \\
\hline$\leq 12$ & 11 & 6 & 54.5 & 3 & 27.3 & 2 & 18.2 & - & - & 1.36 & 1.69 & 0.00 & 3.00 & & \\
\hline $13-24$ & 16 & 11 & 68.8 & 2 & 12.5 & 2 & 12.5 & 1 & 6.3 & 1.38 & 2.42 & 0.00 & 2.75 & & \\
\hline $25-36$ & 7 & 6 & 85.7 & - & - & 1 & 14.3 & - & - & 0.71 & 1.89 & 0.00 & 0.00 & & \\
\hline $37-60$ & 9 & 7 & 77.8 & 1 & 11.1 & 1 & 11.1 & - & - & 0.78 & 1.72 & 0.00 & 1.00 & & \\
\hline$>60$ & 17 & 13 & 76.5 & 1 & 5.9 & 2 & 11.8 & 1 & 5.9 & 1.18 & 2.38 & 0.00 & 1.00 & & \\
\hline
\end{tabular}

Abbreviations: IQR, interquartile range; SD, standard deviation.

relationships were observed between the severity of nausea and age, level of education, place of residence, occupation, and the duration of the disease $(P>0.05)$.

As shown in Table 4 regarding the relationship between the severity of vomiting and the demographic variables, no significant relationships were observed between the severity of vomiting and any of the studied variables $(P>0.05)$.

\section{Discussion}

A total of $56.7 \%$ of the subjects examined in the present study were male and $43.3 \%$ were female. In a study conducted by Ghahri Sarabi et al on dialysis complications and their related factors in hemodialysis patients in select hospitals of Hamadan province, from the total of 192 subjects, $59.9 \%$ were male and $40.1 \%$ were female (17). Several other studies have also reported a larger number of male patients compared to females (18-22). Unlike the present findings, in a study by Shahdadi et al to compare nausea and vomiting during hemodialysis in the supine position and the half-sitting position, of the total of 45 patients, $64.6 \%$ were female and the rest were male (23). Given that hypertension is the second most common cause of CKD $(4,24)$, the risk of ESRD as a result of nephropathy due to hypertension is higher in men than in women (25).
Hus et al argued that men have a higher hematocrit level and thus a higher GFR than women and proposed that these higher levels contribute to the greater incidence of kidney dysfunction among men than among women (26). The majority of the subjects in the present study (51.7\%) belonged to the age group of 60 and above and only a minority $(8.3 \%)$ were below the 20 to 39 age range; the mean age of the subjects was 59.5 years. In a study by Mottahedian-Tabrizi et al, the mean age of the examined hemodialysis patients was 55.05 (18). Accordingly in the study by Monfared et al, most of the patients were over 60 and belonged to the age group of 45-64 (20). Additionally in the study by Ghahri Sarabi et al, the mean age of the subjects was 54.8 and their age range was 20 to 80 (17). Older people are at a greater risk of developing certain kidney and urinary tract diseases such as inflammation of the kidneys, diabetes, urinary tract infections, urinary incontinence, renal artery diseases, and hypertension; as a result, the incidence of CKD increases with age and patients with kidney failure tend to be middle-aged (27). The majority of the subjects examined in the present study $(38.7 \%)$ were retired and only a minority $(1.7 \%)$ worked for governmental organizations. In the study of Ghahri Sarabi et al, however, most of the subjects were unemployed (31.3\%) and housewives (27.7\%) (17). The mean duration 
Table 4. Distribution, mean, SD, median, IQR of severity of vomiting in hemodialysis patients according to gender, age, educational level, residential area, job, and disease duration

\begin{tabular}{|c|c|c|c|c|c|c|c|c|c|c|c|c|c|c|c|}
\hline \multirow{3}{*}{ Characteristics } & \multirow{3}{*}{$\mathrm{n}$} & \multicolumn{8}{|c|}{ Severity of vomiting } & \multirow{3}{*}{ Mean } & \multirow{3}{*}{ SD } & \multirow{3}{*}{ Median } & \multirow{3}{*}{ IQR } & \multirow{3}{*}{$r$} & \multirow{3}{*}{$P$} \\
\hline & & \multicolumn{2}{|c|}{ No Nausea } & \multicolumn{2}{|c|}{ Mild } & \multicolumn{2}{|c|}{ Moderate } & \multicolumn{2}{|c|}{ Severe } & & & & & & \\
\hline & & No. & $\%$ & No. & $\%$ & No. & $\%$ & No. & $\%$ & & & & & & \\
\hline Gender & & & & & & & & & & & & & & - & 0.102 \\
\hline Female & 26 & 21 & 80.8 & 3 & 11.5 & 2 & 7.7 & - & - & 1.27 & 0.60 & 1.00 & 0.00 & & \\
\hline Male & 34 & 32 & 94.1 & 2 & 5.9 & 0 & 0.0 & - & - & 1.06 & 0.24 & 1.00 & 0.00 & & \\
\hline Age (y) & & & & & & & & & & & & & & 0.007 & 0.956 \\
\hline$<50$ & 15 & 14 & 93.3 & 1 & 6.7 & - & - & - & - & 1.07 & 0.26 & 1.00 & 0.00 & & \\
\hline $50-59$ & 14 & 11 & 78.6 & 1 & 7.1 & 2 & 14.3 & - & - & 1.36 & 0.74 & 1.00 & 0.25 & & \\
\hline $60-69$ & 12 & 11 & 91.7 & 1 & 8.3 & - & - & - & - & 1.08 & 0.29 & 1.00 & 0.00 & & \\
\hline$\geq 70$ & 19 & 17 & 89.5 & 2 & 10.5 & - & - & - & - & 1.11 & 0.31 & 1.00 & 0.00 & & \\
\hline Educational level & & & & & & & & & & & & & & 0.139 & 0.290 \\
\hline Illiterate & 9 & 9 & 100 & - & - & - & - & - & - & 0.00 & 0.00 & 0.00 & 0.00 & & \\
\hline Primary & 22 & 19 & 86.4 & 3 & 13.6 & - & - & - & - & 1.14 & 0.35 & 1.00 & 0.00 & & \\
\hline Intermediate & 11 & 11 & 100 & - & - & - & - & - & - & 0.00 & 0.00 & 0.00 & 0.00 & & \\
\hline Secondary & 12 & 8 & 66.7 & 2 & 16.7 & 2 & 16.7 & - & - & 1.50 & 0.80 & 1.00 & 1.00 & & \\
\hline Diploma+ & 6 & 6 & 100 & - & - & - & - & - & - & 0.00 & 0.00 & 0.00 & 0.00 & & \\
\hline Residential area & & & & & & & & & & & & & & - & 0.659 \\
\hline City & 55 & 48 & 87.3 & 5 & 9.1 & 2 & 3.6 & - & - & 1.16 & 0.46 & 1.00 & 0.00 & & \\
\hline Rural & 5 & 5 & 100 & - & - & - & - & - & - & 0.00 & 0.00 & 0.00 & 0.00 & & \\
\hline Job & & & & & & & & & & & & & & - & 0.441 \\
\hline Housekeeper & 22 & 18 & 81.8 & 2 & 9.1 & 2 & 9.1 & - & - & 1.27 & 0.63 & 1.00 & 0.00 & & \\
\hline Retired & 23 & 21 & 91.3 & 2 & 8.7 & - & - & - & - & 1.09 & 0.29 & 1.00 & 0.00 & & \\
\hline Others & 15 & 14 & 93.3 & 1 & 6.7 & - & - & - & - & 1.07 & 0.26 & 1.00 & 0.00 & & \\
\hline Disease duration (mon) & & & & & & & & & & & & & & 0.023 & 0.860 \\
\hline$\leq 12$ & 11 & 10 & 90.9 & 1 & 9.1 & - & - & - & - & 1.09 & 0.30 & 1.00 & 0.00 & & \\
\hline $13-24$ & 16 & 13 & 81.3 & 2 & 12.5 & 1 & 6.3 & - & - & 1.25 & 0.58 & 1.00 & 0.00 & & \\
\hline $25-36$ & 7 & 7 & 100 & - & - & - & - & - & - & 0.00 & 0.00 & 0.00 & 0.00 & & \\
\hline $37-60$ & 9 & 9 & 100 & - & - & - & - & - & - & 0.00 & 0.00 & 0.00 & 0.00 & & \\
\hline$>60$ & 17 & 14 & 82.4 & 2 & 11.8 & 1 & 5.9 & - & - & 1.24 & 0.56 & 1.00 & 0.00 & & \\
\hline
\end{tabular}

Abbreviations: IQR, interquartile range; SD, standard deviation.

of hemodialysis was 46.32 months, and in most of the subjects, this duration exceeded 48 months (26.7\%). In the study of Mottahedian-Tabrizi et al, $70 \%$ of the patients had a history of hemodialysis for 40-60 months (18). Moreover, in the study by Mirzaei and Azimian, the mean duration of hemodialysis was 31.75 months (13). However, in the study of Ghahri Sarabi et al, most of the subjects had a duration of hemodialysis of less than 2 years with a mean of 4.8 years (17).

The results obtained in this study regarding the incidence and severity of nausea during hemodialysis revealed the incidence of nausea as $28.3 \%$ with a mean severity of $1.15 \pm 2.08$. In the study of Mottahedian-Tabrizi et al, the incidence of nausea during hemodialysis was $33.3 \%$ in the subjects with routine nursing care (18), which is higher than the rate reported in the present study. in the study of Ghahri Sarabi et al on the incidence of hemodialysis complications, the incidence of nausea was reported as 9.4\% (17). Accordingly in the Chong and Tan study on the incidence of gastrointestinal symptoms in Asian patients undergoing regular hemodialysis reported the incidence of nausea as $18.2 \%$ (12), which is lower than the rate reported in the present study.

The results obtained in this study regarding the incidence and severity of vomiting during hemodialysis revealed the incidence of vomiting as $11.7 \%$ with a mean rank of vomiting severity of 2.08. In the study of Motahedian Tabrizi et al, the incidence of vomiting during hemodialysis was $16.7 \%$ in the subjects with routine nursing care (18), which is higher than the rate reported in the present study. In the study of Sarabi et al on the incidence of hemodialysis complications, the incidence of vomiting was reported as $2.1 \%$ (17). In Chong and Tan study on the incidence of gastrointestinal symptoms in Asian patients undergoing regular hemodialysis, the incidence of vomiting was reported as $9.8 \%$ (12), which is lower than the rate reported in the present study.

There are different mechanisms at play in the incidence of nausea and vomiting during hemodialysis. Many patients experience this complication during dialysis due to the rapid drop in their blood pressure or urea (14). Other causes of nausea and vomiting include fever response to municipal water and other materials, disequilibrium syndrome, anxiety, and general causes of nausea and vomiting (4). The multiple etiology of the effects of ESRD and its treatment on the digestive system, the patient's diet, medication regimen, and developed disabilities are also considered major causes of nausea and vomiting. Fluid overload is associated with mucosal edema in the gastrointestinal system (along with early satiety), nausea, vomiting, and diarrhea (12). Nausea 
and vomiting can also be early signs of disequilibrium syndrome. Both type A and type B dialyzer reactions cause these symptoms. Increased dialysate sodium and calcium may aggravate nausea and vomiting in dialysis patients (24). Eating while on dialysis machine or less than one hour before the start of dialysis can cause nausea during hemodialysis (28). Body position during hemodialysis also affects the incidence of nausea; according to the results obtained by Shahdadi et al, the supine position causes more nausea and vomiting compared to the half-sitting position (23).

The present study revealed a significant relationship between gender and the severity of nausea during hemodialysis, as the severity of nausea was higher in women than in men. No relationships were observed between any of the other variables and the incidence and severity of nausea and vomiting. The proven relationship between fear, anxiety, and depression and the incidence and severity of nausea, and the greater incidence of fear, anxiety and depression in women than in man $(29,30)$ can justify the significant relationship observed between gender and the severity of nausea during hemodialysis.

\section{Conclusion}

There is a relatively high incidence of nausea and vomiting in hemodialysis patients. Nurses are therefore recommended to further consider these complications and to seek appropriate ways to reduce their incidence and severity in hemodialysis patients by performing applied research and evaluating appropriate interventions.

\section{Limitations of the study}

Despite all the efforts made by the researchers, this study had some limitations. One of the limitations was that nausea is a subjective phenomenon and there are no objective criteria for measuring it; the researchers therefore had to rely on the patients' answers to measure this complication.

\section{Acknowledgements \\ This paper is part of a postgraduate thesis (Fatemeh Asghari) that was approved by Semnan University of Medical Sciences under the code 579. Therefore, we would like to express our gratitude to the research deputy of Semnan University of Medical Sciences for all their financial support and also the authorities, nursing personnel and patients of the dialysis units of Semnan Kowsar and Garmsar Emam Khomeini Hospitals for their sincere cooperation. Also we would like to thank the Clinical Research Development Unit of Kowsar Educational and Research and Therapeutic Center of Semnan University of Medical Sciences for providing facilities to this work.}

\section{Conflicts of interest}

All authors declare that they have not had any conflicts of interest in conducting the present study.

Authors' contribution

MRA, FA and NHM collected the data and recruited the patients. RG and FR performed the statistical analysis. MRA wrote the paper. AAG edited the final draft. All authors signed the manuscript.

Ethical considerations

Ethical issues (including plagiarism, misconduct, data fabrication, falsification, double publication, and redundancy) have been completely considered by the authors.

\section{Funding/Support}

This study was supported by Semnan University of Medical Sciences (Grant \#579).

\section{References}

1. Rafii F, Soleimani M, Seyedfatemi N. A model of patient participation with chronic diseases in nursing care. Koomesh. 2011;12:293-304.

2. World Health Organization (WHO). Innovative Care for Chronic Condition: Building Blocks for Action. Geneva: WHO; 2002.

3. Monahan FD, Sands JK, Neighbors M, Marek JF, Green CJ. Phipp's Medical-surgical Nursing: Health and Illness Perspectives. 8th ed. St. Louis: Mosby; 2007.

4. Asgari MR, Soleimani M. Intensive Care in ICU, CCU and Dialysis Wards. 28th ed. Tehran: Boshra; 2014.

5. Ghods AA, Hoseini Abforosh N, Ghorbani R, Asgari MR. The effect of topical application of lavender essential oil on the intensity of pain caused by the insertion of dialysis needles in hemodialysis patients: a randomized clinical trial. Complement Ther Med. 2015;3:325-330. doi: 10.1016/j.ctim.2015.03.001.

6. Rambod M, Rafii F, Hosseini F. Quality of life in patients with end stage renal disease. Hayat. 2008;14:51-61.

7. Asgari MR, Mohammadi E, Fallahi Khoshknab M, Tamadon MR. Hemodialysis patients' perception from nurses' role in their adjustment with hemodialysis: a qualitative study. Koomesh. 2011;12:385-395.

8. Longo DL, Kasper DL, Jameson JL, Fauci AS, Hauser SL, Loscalzo J, et al. Harrison's Principles of Internal Medicine. 18th ed. New York: McGraw-Hill; 2012.

9. Smeltzer SC, Bare B, Hinkle J, Cheever K. Brunner and Suddarth's Textbook of Medical-Surgical Nursing. 12th ed. Philadelphia: Lippincott; 2010.

10. Kazemini M, Nafar M, Aghili M, Heidari A. Renal replacement therapy in Iran. J Hakim. 2003;6:11-7.

11. Devenport A. Intradialytic complications during hemodialysis. Hemodial Int. 2006;10:162-7. doi: $10.1111 / \mathrm{j} .1542-4758.2006 .00088 . \mathrm{x}$

12. Chong VH, Tan J. Prevalence of gastrointestinal and psychosomatic symptoms among Asian patients undergoing regular hemodialysis. Nephrology. 2013;18:97103. doi: $10.1111 /$ nep. 12000 .

13. Mirzaei DR, Azimian M. Neurological complications of hemodialysis in hemodialysis patients. Iran J Neurosurg 2009;8:458-464.

14. Discovering Dialysis a manual for kidney and dialysis patients. Renal Failure and Dialysis. http://www. kidneyfoundation.com. Accessed September 4, 2011.

15. Cladian B, Walter B, Daneiela G, Thamas K, Wolfagang R, Ralf S. Characteristics of hypotention-prone hemodialysis patient: is critical relative blood volume. Nephrol Dial 
Transplant. 2003;18:1353-60.

16. Korttila K. The study of postoperative nausea and vomiting. Br J Anaesth 1992;69:20S-3S.

17. Ghahri Sarabi AR, Torabi M, Abed Saeidi G, Akbarzade Baghban AR. Assessment of Complications during Hemodialysis and its relative factors in patients under hemodialysis in selected hospitals in Hamadan province. J Nurs Midwifery Coll Shahid Beheshti Univ Med Sci 2011;21:37-44.

18. Mottahedian-Tabrizi E, Najafi Mehri S, Samiey S, Einollahi B, Babaei G, Mohammadi E. Effect of programmed nursing cares in prevention of hemodialysis complications. Iran J Crit Care Nurs. 2009;2:55-9.

19. Zou C, Yang L, Wu Y, Su G, Chen S, Guo X, et al. Auricular acupressure on specific points for hemodialysis patients with insomnia: a pilot randomized controlled trial. Plos One 2015;10:e0122724. doi: 10.1371/journal.pone.0122724.

20. Monfared A, Khosravi M, Orang Pour R, Mousavian Roshan Zamir A, Aghajani Nargesi D. Assessment the causes of chronic renal failure in Gilan hemodialysis patients. J Gilan Med Sci Univ. 2003;46:76-81.

21. Sabouhi F, Kalani L, Valiani M, Mortazavi M, Bemanian M. Effect of acupressure on fatigue in patients on hemodialysis. Iranian J Nurs Midwifery Res. 2013;18:429-34.

22. Shariati A, Jahani S, Hooshmand M, Khalili N. The effect of acupressure on sleep quality in hemodialysis patients. Complement Ther Med. 2012;20:417-423. doi: 10.1016/j. ctim.2012.08.001.

23. Shahdadi H, Badakhsh M, Moein AA, Shahreki A.
Comparison on nausea \& vomiting between supine and semi fowler position during hemodialysis. J Mazandaran Univ Med Sci. 2008;18:58-63.

24. Atabak S, Aghayani K, Tamaddondar M, Jalalzadeh H, Hakemi M, Rejlani H, et al. Nurse and Dialysis. 1st ed. Tehran: Soha; 2007.

25. Noblat AC, Lopes MB, Lopes GB, Lopes AA. Complications of hypertension in men and women seen in a referral outpatient care unit. Arq Bras Cadiol. 2004;86:314-19. doi: 10.1590/S0066-782X2004001600006.

26. Hus C, Bates WD, Kuperman GJ, Curhan GC. Relationship between hematocrite and renal function in men and women. Kidney Int. 2001;59:725-31. doi: 10.1046/j.15231755.2001.059002725.x.

27. Baraz S. Comparative assessment of the effects of 2 conventional and distance self-care programs on problems and quality of life in patient undergoing dialysis [Dissertation] Tehran: Tarbiat Modarres University; 1994.

28. Osareh S, Miladipour AH, Rahmani L, Rahimzadeh A, Rajolani H, Hakam M, et al. Nurse and Renal Failure. 1st ed. Tehran: Tandis; 2008.

29. Kaviani H, Ahmadi Abhari A. Prevalence of anxiety disorders in Tehran city. Iran J Psychiatr Clin Psychol. 2003;8:4-11.

30. Nazari T, Yassemi M T, Doust-Mohammadi M, Nematzadeh Mahani K. Prevalence of depression and anxiety among patients in internal and surgical wards. Iran J Psychiatr Clin Psychol. 2002;8:18-25.

Copyright @ 2017 The Author(s); Published by Nickan Research Institute. This is an open-access article distributed under the terms of the Creative Commons Attribution License (http://creativecommons.org/licenses/by/4.0), which permits unrestricted use, distribution, and reproduction in any medium, provided the original work is properly cited. 